\title{
Air residues from live firings during military training
}

\author{
E. Diaz ${ }^{1}$, S. Savard ${ }^{2} \&$ I. Poulin ${ }^{1}$ \\ ${ }^{1}$ Defence Research and Development Canada, Valcartier, Canada \\ ${ }^{2}$ Centre de Recherche Industrielle du Québec, Canada
}

\begin{abstract}
Air and particulate emissions are a growing concern in military activities, specifically for two aspects: live-firing training and demilitarization. In the last five years, this topic took a larger place among defence projects. The Canadian Department of National Defence performed trials to sample air and particulate emissions from firings of various Canadian ammunition: small arms $(9 \mathrm{~mm}$, $7.62 \mathrm{~mm}, 5.56 \mathrm{~mm}, 0.50 \mathrm{cal}$ and $0.338 \mathrm{cal})$ and large calibres $(60,84,105$ and $155 \mathrm{~mm})$. In addition, the United-States Department of Defence started, in collaboration with US EPA, a program of characterization of air emissions from open burning and open detonation in a demilitarization context. Canada shares the same interest and also wants to determine the nature and the quantity of substances spread in the environment from open burning and open detonation. This paper will present an overview of the sampling method developed at Defence Research and Development Canada, Valcartier in collaboration with the "Centre de Recherche Industrielle du Québec" to collect gas and particulate emissions at the muzzle of a gun from live-firings during military training. Combustion gases, semi-volatile and volatile organic compounds and particle emissions were measured with two different methods: outdoor and indoor (confined). In the following years, DRDC will try to establish a correlation between the collected data and their potential toxicity in order to determine if these activities can have an impact on human health.
\end{abstract}

Keywords: artillery live-firing, air emissions, SVOC, VOC, particles. 


\section{Introduction}

Environmental impacts of military training in ranges and training areas (RTAs) are well understood and the literature defines the contamination for different locations (firing positions, target areas) and also for the different ranges (small arms, anti-tank, grenade and demolition ranges). Moreover, residues generated on the ground in front of the muzzle of the gun are also well documented. Then, soil, biomass, surface and groundwater contaminations are generally well characterized at the military bases. However, the air characterization from live firing of various weapons is not well understood and studied. In fact, there are only a few studies in the literature on gas and particle emissions from live firing of weapons.

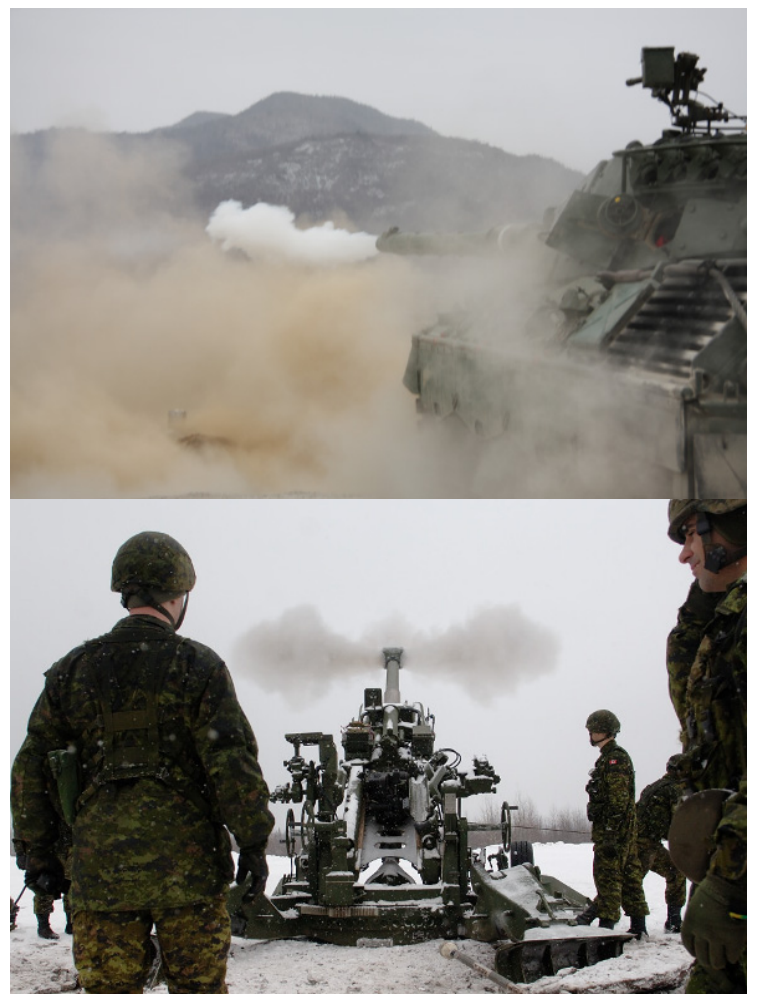

Figure 1: $\quad$ Emissions from the live firing of 105-mm tank and 155-mm M777.

At DRDC Valcartier, a new project on the characterisation of air residues was started in 2006 in an effort to complete the environmental assessment of the impact of military training. This knowledge fill the gap found in the field of air emissions. The major objective of this study was, first, to develop a protocol to determine the airborne emissions (particles and gases) at the muzzle of different guns, second, to use this data to validate the theoretical prediction from 
thermodynamics codes to calculate performance parameters of ammunition and, third, to confirm that new formulations of gun propellant release less toxic and polluting compounds than current gun propellants. It is important to note that, in this study, health effects on soldiers were not studied.

This project involves some challenges. In fact, the sampling of the plume of contamination directly at the muzzle of the gun is difficult since the sampling material must not be affected or destroyed by the firing. Moreover, it is difficult to use real-time spectroscopy directly in the field since the vibration caused by the blast would have a big influence on the results. In addition, the diffusion of gases is influenced by atmospheric conditions that make difficult the interpretation of results. The broad variety of chemical substances emitted by the combustion of gun propellants makes it difficult to collect and determine all the components resulting from the firing. Finally, the concentrations of air pollutants are generally low, which implicates the need for sensitive analytical and sampling methods. This paper will report the sampling methods for gases and particles at the muzzle of the gun and the results obtained from the outdoor and indoor set ups.

\section{Trial description/method}

\subsection{Gun propellants}

The gun propellant formulation tested in our study is the M1 composition that is a single base propellant containing mainly Nitrocellulose (NC) and 2.4Dinitrotoluene (DNT). The M1 gun propellant is packed in seven charge bags that constitute the so-called M67 charges (referring to the weight distribution and the type of packaging). The exact formulation is $88 \%$ of NC, $8 \%$ of $2.4-\mathrm{DNT}$, $1 \%$ diphenylamine and $3 \%$ dibutylphthalate $[1,2]$. Moreover, one bag contains lead and its mass is $12.7 \mathrm{~g}$.

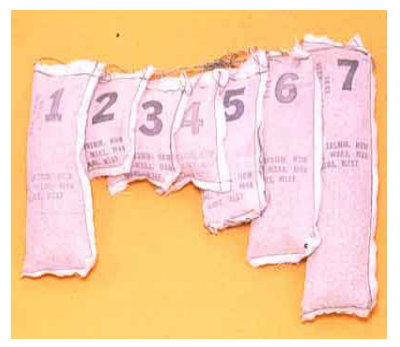

Figure 2: The seven M67 propelling charges containing M1 gun propellant formulation.

\subsection{Trials}

For the trials, two types of set ups were used: 1) one gun outside, as used during military training and; 2) one gun indoor, linked to a muffler at one end (see Figure 4), to sample gases and particles in a confined area. 


\subsubsection{The outdoor set-up with the 105-mm Howitzer gun}

Figure 3 shows the outdoor set-up used to collect gases and particles from livefiring with a 105-mm Howitzer gun. As demonstrated in Figure 3, the sampling station was located at $5 \mathrm{~m}$ from the muzzle of the gun and offset $2 \mathrm{~m}$ to the right (if one is positioned in front of the gun facing it). In this configuration, it was possible to capture the plume of contaminants in order to collect gas and particles without affecting and/or destroying the sampling station and equipment (filters, tubes, pipe, etc.). The stainless steel box on the right side of the picture protected the pumps and the bags used for collecting the combustion gases.

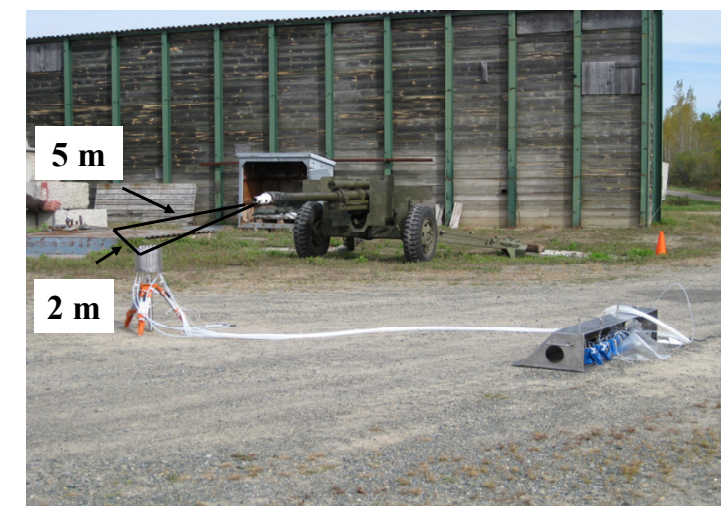

Figure 3: $\quad$ Outdoor set-up for air emissions sampling at the muzzle of the 105mm gun.

\subsubsection{The indoor set-up with the 105-mm Howitzer in the Muffler facility at Nicolet, Quebec}

At the Nicolet experimental site, near Trois-Rivières, Province of Quebec, Canada, there is a facility called the Muffler that can be modified to collect and, consequently, study the gases and particles emitted from live-firing using a $105 \mathrm{~mm}$ gun in a confined environment. Figure 4 shows the Muffler with the $105 \mathrm{~mm}$ Howitzer gun at its end. This equipment was originally developed to reduce the noise of live firings. This installation allows the collection of more concentrated samples than with the outdoor set-up. In fact, the dilution effect observed with the outdoor set-up did not occur with the indoor one. However, it is important to validate the results obtained from this set-up, because the confined area affects concentration, hence can change the thermodynamics of the combustion. In fact, the more realistic model is the outdoor one, since the quantity of gas and particles was the same as in real military training. However, with the dilution occurring outside, the characterisation of all emitted gases and particles can be difficult. For this reason, the sampling from the Muffler is better suited to determine all the substances into the contamination plume. Figure 5 shows the pumps and tubes placed at approximately $10 \mathrm{~m}$ of the muzzle of the gun, located inside the Muffler. 


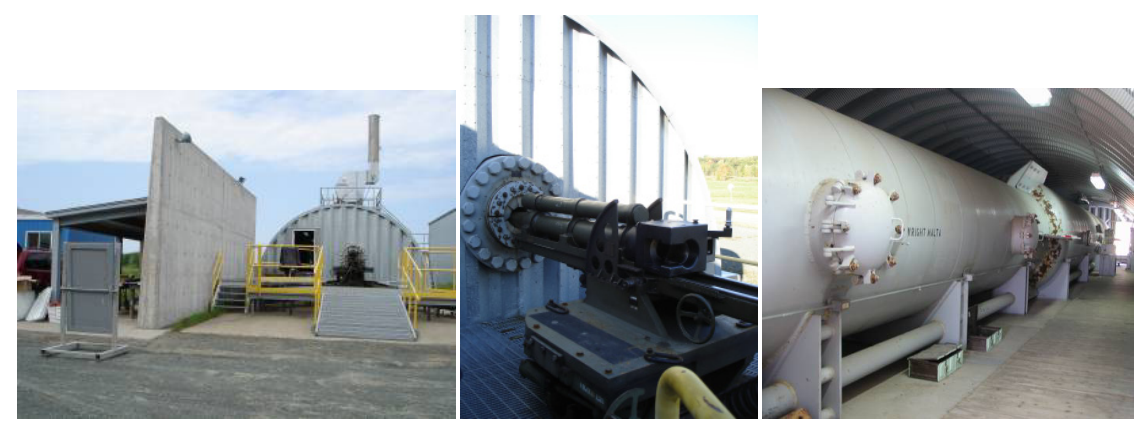

Figure 4: $\quad$ Muffler installation to collect air samples at the muzzle of the gun in a confined area.
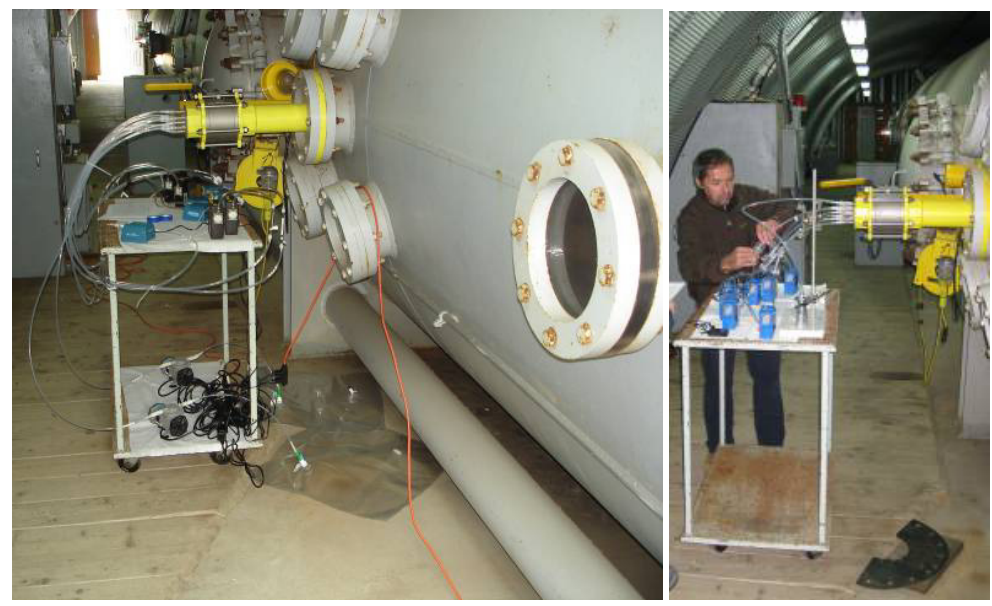

Figure 5: Sampling station at the Muffler installation.

\subsubsection{Analytical methods and sampling media}

Table 1 gives the media used for the sampling and the analytical methods used to determine the concentrations of the different parameters of interest. The combustion gases $\left(\mathrm{CO}, \mathrm{CO}_{2}, \mathrm{CH}_{4}, \mathrm{NO}_{2}, \mathrm{~N}_{2} \mathrm{O}, \mathrm{SO}_{2}, \mathrm{H}_{2} \mathrm{O}\right.$ and $\left.\mathrm{NH}_{3}\right)$ were analysed by Fourier Transform Infrared Spectroscopy (FTIR). Mercury (Hg) and hydrogen sulfide $\left(\mathrm{H}_{2} \mathrm{~S}\right)$ vapors were analysed with a Jerome 431-X and 631-X analyzers from Arizona Instrument. Semi-volatile (SVOC) and volatile organic compounds (VOC) were analysed according to US EPA methods TO-15 (using bags instead of canisters since canisters were not available) and TO-17. Finally, inorganic particles, Al, P, S, K, Ca, Cr, Mn, Fe, Ni, Cu, Zn, As, Se, Cd, Pb, Ba, $\mathrm{Sn}$, were determined by Inductively Coupled Plasma Emission Spectroscopy (ICP-AES). 
Table 1: Sampling media and analytical methods used to determine the concentration of the different parameters.

\begin{tabular}{|c|c|c|}
\hline Compounds & Sampling Media & Analytical Methods \\
\hline $\begin{array}{l}\text { Combustion } \\
\text { gases }\end{array}$ & $\begin{array}{c}\text { Tedlar bags } \\
\text { (interrupted): } \\
\text { Outdoor: } 20 \mathrm{~L}, 5 \\
\text { L/min } \\
\text { Muffler : } 60 \mathrm{~L}, 23 \\
\text { L/min }\end{array}$ & $\begin{array}{c}\text { FT-IR and *Jerome } 431-\mathrm{X} \mathrm{Hg} \\
\text { and } 631-\mathrm{X} \mathrm{H}_{2} \mathrm{~S} \text { vapor } \\
\text { analyzer }\end{array}$ \\
\hline VOCs (EPA) & $\begin{array}{c}\text { Carbotrap } 300 \\
\text { (continued) }(0.2 \\
\text { L/min) }\end{array}$ & $\begin{array}{c}\text { Gas Chromatography -Mass } \\
\text { Spectroscopy (MS) }\end{array}$ \\
\hline SVOCs (EPA) & $\begin{array}{c}\text { Carbotrap } 300 \\
\text { (continued) }(0.2 \\
\text { L/min) }\end{array}$ & $\begin{array}{c}\text { Gas Chromatography -Mass } \\
\text { Spectroscopy }\end{array}$ \\
\hline $\begin{array}{l}\text { Organic } \\
\text { particles } \\
\text { (explosives } \\
\text { residues) }\end{array}$ & $\begin{array}{c}\text { Supelco orbo-402 } \\
\text { Tenax }\end{array}$ & $\begin{array}{c}\text { High Pressure Liquid } \\
\text { Chromatography -MS (or UV) }\end{array}$ \\
\hline $\begin{array}{c}\text { Inorganic } \\
\text { particles } \\
\text { (derived from } \\
\text { NIOSH 0500) } \\
\end{array}$ & $\begin{array}{c}\text { Filters (outdoor : } 2.5 \\
\text { L/min; Muffler : } \\
\text { 2L/min) } \\
\text { Cascade impactor }\end{array}$ & ICP-AES \\
\hline
\end{tabular}

Filters (see Figure 6) and a cascade impactor (see Figure 7) were used to collect organic and inorganic particles. The cascade impactor (multi-orifice and multi-stage cascade impactor, Marple Personal Cascade Impactors, series 290, Thermo Electron Corporation) provides the particle size distribution. At each step, a circular filter called the substrate was placed and it was analysed at the end of the sampling to determine the particle size distribution of inorganic particles. The distribution of the particles at the different stages is dependent on their size (the impactor has height stages). The larger particles were stopped at the higher levels while the smaller ones reach the lower stages.

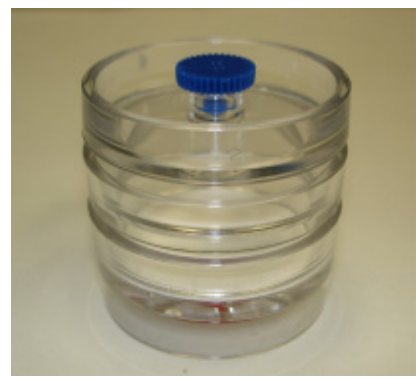

Figure 6: $37 \mathrm{~mm}$ diameter filter with $0.8 \mu \mathrm{m}$ pores. 


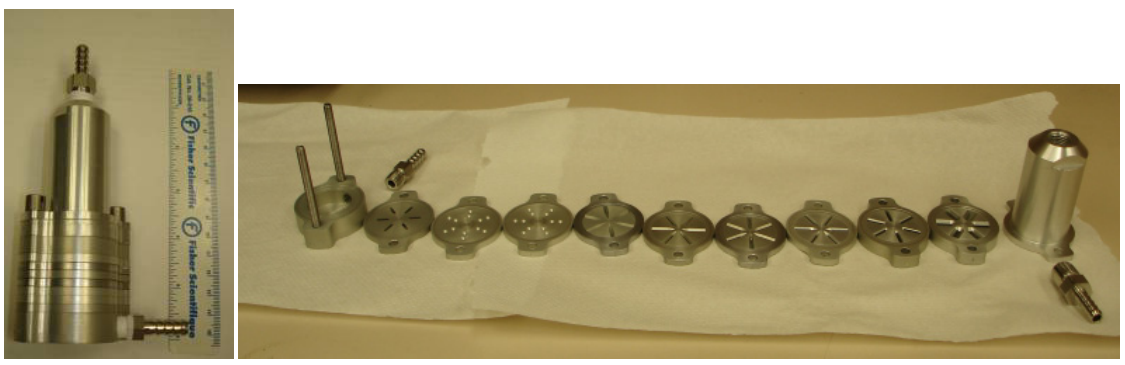

Figure 7: Assembled and disassembled cascade impactor.

\section{Results}

In this section, results from the outdoor and indoor (confined) set ups are compared. The first verification made is the oxygen content of the two set ups. A certain quantity of oxygen is necessary to ensure a complete combustion. If there is a lack of oxygen in the confined area, the combustion products will be different between the two types of firings (confined and unconfined). In the analysis, 20.9 and $20.5 \%$ of oxygen in the air for the outdoor and the indoor setup, respectively, were measured after the firings [3]. These percentages are very similar showing that the products of combustion are not affected by this parameter. There are many advantages to using the Muffler; it increases the concentration of gases by a factor between 10 and 1000, and the number of particles collected during firings by a factor of 10 . Then, with the Muffler, it is possible to confirm with a greater certainty the nature of the different substances emitted from live firings and to detect new substances that can be difficult or impossible to detect outside because of the dilution factor and because of the detection limits of our analytical methods. From the Muffler, it has been possible to detect two additional combustion gases, 40 new VOCs, almost all aromatics, and 36 new SVOCs. All these additional compounds released during the combustion were not detected from the outdoor set-up. Moreover, results showed that the confinement does not alter the nature of the gases of combustion, which is an important aspect in the validation of the Muffler model.

Table 2 reports the main combustion gases for the two set ups, while Table 3 regroups the concentrations of the main VOCs and SVOCS. As mentioned at Section 2.2.3, two different methods were used to sample VOCs and SVOCs, i.e. the EPA US Methods TO-15 and TO-17. Method TO-15 used bags to collect the gases while method TO-17 used absorbant tubes. The concentrations found from bags were lower than for absorbant tubes since the volume collected into bags was limited to $20 \mathrm{~L}$ instead of unlimited for the tubes. For this reason, only the results from the method TO-17 were shown in Table 3. To perform this comparison, results in Tables 2 and 3 were those obtained from the burning of six bags of gun propellant.

Concerning the combustion gases, carbon monoxide, methane and ammonia are the major detected gases. The concentration of carbon dioxide was also 
significant, but its concentration in ambient air is also important. For the VOCs, benzene and toluene were the most abundant. In general, VOC concentrations were lower than $100 \mu \mathrm{g} / \mathrm{m}^{3}$. Concerning the SVOCs, naphthalene is the most important one.

Table 2: $\quad$ Main combustion gases obtained after the firing of six bags.

\begin{tabular}{|c|c|c|}
\hline Combustion gases & Outdoor set-up & Muffler \\
\hline $\mathrm{O}_{2}(\%)$ & 20.9 & 20.5 \\
\hline $\mathrm{CO}(\mathrm{ppm})$ & 50 & 5000 \\
\hline $\mathrm{CO}_{2}(\mathrm{ppm})$ & 500 & 1800 \\
\hline $\mathrm{CH}_{4}(\mathrm{ppm})$ & 9 & 100 \\
\hline $\mathrm{NH}_{3}(\mathrm{ppm})$ & $<3$ & 70 \\
\hline $\mathrm{SO}_{2}(\mathrm{ppm})$ & $<5$ & 40 \\
\hline $\mathrm{NO}_{2}(\mathrm{ppm})$ & $<3$ & $<3$ \\
\hline $\mathrm{H}_{2} \mathrm{~S}(\mathrm{ppm})$ & 0.06 & 1.2 \\
\hline $\mathrm{Hg}_{\left(\mathrm{mg} / \mathrm{m}^{3}\right)}$ & 0.09 & 0.04 \\
\hline
\end{tabular}

Table 3: $\quad$ Main VOCs and SVOCs detected after the firing of six bags.

\begin{tabular}{|c|c|c|}
\hline Compounds & $\begin{array}{c}\text { Muffler } \\
\left(\mu \mathrm{g} / \mathrm{m}^{3}\right)\end{array}$ & $\begin{array}{c}\text { Outdoor set-up in } \\
\text { front of the fun } \\
\left(\mu \mathrm{g} / \mathrm{m}^{3}\right)\end{array}$ \\
\hline Benzene & 1600 & 40 \\
\hline Toluene & 50 & 10 \\
\hline Styrene & 12 & 0.8 \\
\hline Benzonitrile & 17 & 1.6 \\
\hline Naphtalene & 22 & 0.8 \\
\hline Phenanthrene & 12 & 0 \\
\hline Carbazole & 22 & 0 \\
\hline Di-n-butyl phthalate & 36 & 0 \\
\hline
\end{tabular}


Lead, potassium, sulphur, iron and copper were detected with a diameter inferior to $2 \mu \mathrm{m}$. The average amounts of particles measured ranged between 160 and $210 \mathrm{mg} / \mathrm{m}^{3}$ and between 240 and $300 \mu \mathrm{g} / \mathrm{m}^{3}$ from the indoor gun (Muffler) and the outside gun, respectively. Inorganic particles were measured from an 8stage cascade impactor allowing the differentiation of particle sizes from 0.52 to $21.3 \mu \mathrm{m}$ with the Muffler set-up, since the masses of particles from the outside set-up were not concentrated enough to allow this type of measurement. Moreover, iron oxide was detected only for the Muffler and this result was explained by the fact that firings shook the walls of the Muffler and iron particles were probably released in the muffler during the sampling. Iron particles did not come from the gun propellant combustion, but from the Muffler walls. The comparison of the lead concentrations in the two set ups shows that we found $700 \mu \mathrm{g} /$ filter after four firings at charge 6 in the Muffler and $33 \mu \mathrm{g} /$ filter found after 17 firings at charge 6 with the outdoor set-up. Results from the Muffler with the cascade impactor showed that the mean distribution of all collected particles was $0.93 \mu \mathrm{m}$ and the distribution was between 0.52 and $1.55 \mu \mathrm{m}$. For lead, the mean diameter was located between 0.93 and $1.55 \mu \mathrm{m}$ with a significant amount of particles of a diameter below $0.93 \mu \mathrm{m}$. Moreover, the mean diameter of potassium salt particles was around $0.52 \mu \mathrm{m}$ with a significant quantity between 0.93 and $1.55 \mu \mathrm{m}$. We detected more lead particles than potassium salt particles. In the Muffler, the results for lead showed an approximate concentration of $46 \mathrm{mg} / \mathrm{m}^{3}$.

For organics, such as explosives, High Performance Liquid Chromatography with a UV detector was not sensitive enough to detect organic contaminants.

Finally, the number of bags (propelling charges) used for the firings influenced the results. In fact, the lower the amount of gun propellant used for the firing, the higher the concentration of VOCs and SVOCs. In practice, a lower mass of gun propellant means a lower temperature and pressure during operation, therefore suggesting a less efficient reaction. However, gas concentrations increased with the mass of gun propellant (contrary to the VOC and SVOC), which is another sign that the combustion was more complete when a higher mass of gun propellant was used. For particles, a larger quantity was detected with a larger mass of gun propellant.

\section{Conclusion}

Air sampling of gases and particles were performed with two set ups: an outdoor and an indoor (confined) set-up. The latter was built from a piece of equipment called the Muffler. The sampling protocols at the muzzle of the gun and from the Muffler were well established and the collected data from the two set ups, especially the calculation of gas proportions, allowed the validation of the sampling method with the Muffler. As the gases and particles were spread in a confined area, it is important to verify if the model is realistic compared to the outdoor set-up (which simulates the scenario during military training).

The Muffler facility concentrates gases and particles emitted from firings without changing the chemical composition of the residues (10 to 1000 times 
more concentrated for gas and 10 times more solid particles). With this method, we detected two additional combustion gases, $\mathrm{SO}_{2}$ and $\mathrm{NO}_{2}, 40$ new VOCs, almost all aromatics, and 36 new SVOCs. Finally, it was noted that with a higher mass of gun propellant, the quantity of combustion gases and the particle number were higher too, while the VOCs and SVOCs concentrations decreased. This last observation means that less the combustion is efficient (fewer bags) and more VOCs and SVOCs, specific to a non-complete combustion, will be present.

\section{Acknowledgement}

The authors of this paper carried out this research on behalf of the Government of Canada and, as such, the copyright in the paper belongs to the Crown, that is to the Canadian Government.

\section{References}

[1] US Army Defense Ammunition Center, Logistic review and technical assistance office, Savanna, Illinois, 61074 9639, "Propellant Management Guide", June 1998.

[2] Dontsova, K.M., Pennington, J.C., Hayes, C., Simunek, J., Williford, C.M., "Dissolution and transport of 2,4-DNT and 2,6-DNT from M1 propellant in soil", Chemosphere, Volume: 77, Issue: 4, Publisher: Elsevier Ltd, Pages: 597-603, 2009.

[3] Savard, S. and Hardy, M.J., "Émissions gazeuse à la bouche d'un canon, rapport d'étape phase I, essai 2", Report \# 640-PE35480, contrat \# W77017-1924/A, Centre de Recherche Industrielle du Québec, Québec, Québec, Canada, November 2008.

[4] Savard, S. and Hardy, M.J., "Émissions gazeuse à la bouche d'un canon, rapport d'étape phase II, essai 1", Report \# 640-PE35480, contrat \# W77017-1924/A, Centre de Recherche Industrielle du Québec, Québec, Québec, Canada, March 2009.

[5] Savard, S. and Hardy, M.J., "Émissions gazeuse à la bouche d'un canon, rapport d'étape phase II, essai 4", Report \# 640-PE35480, contrat \# W77017-1924/A, Centre de Recherche Industrielle du Québec, Québec, Québec, Canada, July 2010. 